\title{
Transition Strategies for Newcomers to the French School Milieu in Ontario
}

\author{
Marie J. Myers \\ Queen's University, Canada
}

\begin{abstract}
This is a follow-up on a previous study on school age French first language newcomers to English speaking Ontario that showed attitudes and concerns around welcoming strategies and integration policies put in place at the Provincial level. New paths were delineated as a result of recommendations made. The findings led to the formulation of policy recommendations as well as follow-up guidelines for the French school system in Ontario, keeping in mind newcomers' needs as well as looking at the local community where these persons were interacting, namely as regards welcoming mechanisms and strategies to facilitate integration into the community. Since then, a number of implementations have been made in order to follow-up on initial observations regarding points such as the need to take into account attitudes towards diversity and the need of a collective effort. In this paper we discuss the study results, compare the ways implementations were made as well as report on the present situation through the analysis of several recent Ministry documents. The most interesting aspect emerging from the process appears to be the consistency in which consecutive Ministry documents address the relevant issues with a progressive zeroing in on detail as if using a zoom lens with the intention for objectives to be met through progressive adjustments. Overall, the diverse documents published, including the recently recommended implementation guidelines to 'support each pupil' appear to satisfy most concerns expressed in the initial study.
\end{abstract}

\section{Introduction}

Immigration is crucial for the sustainment of the Canadian population. The emphasis in education is on equity and quality, with a realization for the need of lifelong learning and freedom of choice regarding the chosen location and the type of schooling or employment. Canada has two official languages, French and English, and specific language regions. The majority of immigrants to Canada prefer to stay in large cities where they can meet people from the same cultural origins [3] [10] [11] [12] [13]. This creates a number of problems for those who might feel left behind because they find themselves in unfamiliar territory in smaller communities [11] [31] [32] [41]. A loss of French for French-speaking newcomers ensues [15] as they are assimilated in English speaking urban contexts [2] [14] [16]. Therefore the French communities who receive newcomers have to enhance their welcoming strategies in order to enable them to successfully integrate [21] [22].

According to researchers [1] [20] [37] [38] there is a fundamental need for newcomers to have their identity well-anchored first in their new community, namely by developing and enhancing self-assuredness and self-reliance, a belief in one's own aptitudes and capacities [5] [7]. This cannot be done in isolation and requires a supportive environment [9].

In this article I compare a study of French speaking school age newcomers to French speaking communities in Ontario [36] and the subsequent documents published by the Ministry of Education [30] [31] [32] since the Ontario Government [45] has a plan to increase the number of French speakers in Ontario from $8 \%$ to $12 \%$ by 2013 . The initial 2006 study [36] reports on data collected in a questionnaire administered to all French first language (FL1) School Councils on FL1 newcomers covering the four previous years. As well as the research report to the Ministry of Education, reports on the findings of that study were published in previous articles.

The fact that many newcomers' school age children did not enroll in French (FL1) schools despite a policy to that effect, made me wonder what schools the other possible French speaking school age newcomers to Ontario went to, and why. If the intent was to increase the Province's French speaking population, by them not enrolling in French schools there is no componential increase in the FL1 population. Moreover, the fluctuation in these numbers as reported by School Councils over the years just preceding the study was 
cause for concern. From 2001 to 2003 the numbers reported were relatively stable and despite that, even though a large increase was observed during the 20032004 school year, there was overall a clear downward tendency. Hence it was important to explore the reasons for this decline in pupils in French speaking schools.

In a subsequent document "A Cultural Approach to Teaching for an Appropriation of Culture in French Language Schools in Ontario: Orientation and intervention framework" (Our translation) [31], specific measures possibly stemming from recommendations made [36] do not refer directly to the concerns around the welcoming and integration of French speaking newcomers to FL1 language schools in Ontario expressed in the study. Nevertheless many of the problematic issues raised appear to have been very cleverly and tactfully slid into the 2009a document [31] and solutions to almost all major problems are specifically addressed in the later documents, "Support Programme for newcomers" (our translation) [30] and "Admission, welcoming and retention of pupils in Ontario French language schools” (our translation) [32].

In addition, it is important to mention that the contents of [31] were very well received in Ontario and beyond the province, so much so that the recommended measures are being adopted country-wide. In the present article, we report on an analysis of the outcomes of the recommendations in the 2006 study [36] or rather how these appear to have been communicated in the 2009a [31], the 2009b [32] and the 2010 documents [30] mentioned above, by conducting a contrastive analysis of major themes emerging from the four texts.

\section{The study}

The conceptual framework used comes from intercultural communication [23] [25] and from action theory within the context of immigrants from diverse ethnic backgrounds although they are sharing the same mother-tongue with people in the surrounding communities [24] with the obvious implications that are briefly summarized as follows. As reported in the contexts of the study [34] and based on research, the tendency to assume inferiority in fact covers up prejudice. According to researchers [4] [6], often different voices and ways of articulating go unrecognized, unaccepted and unrepeatable. In addition, the historical contexts underlying our actions are often overlooked for the sake of avoiding frictions when words are identified as stemming from them. All our words are thus encapsulated as De Certeau [17] suggests. However, in the context of communication, silencing causes anxiety [4] [6] [28] and other problems. As well, the instructor who tries to silence any student will pay a price. There- fore increasing awareness appears to be another desirable positioning in order to remedy untenable situations. To fully include newcomers requires setting-up spaces in which they feel free [2]. It is further suggested that society creates codes and norms to ensure 'civility' [6], nonetheless these have to be shared with everyone, which implies that 'silence' might be used to keep others from being included and accessing the same information as everyone else, with the obvious consequences attached to such events. Moreover our exchange system based on 'give and take' is problematic as all people do not give back in the competitive contexts that surround us. The fact being that in some culture persons are more used to giving without expecting anything in return might, under certain circumstances, lead to advantage been taken of people who are culturally used to freely give. What is more problematic is what happens when newcomers recognize prejudice in words addressed to them as the suggestion is made [27] that they experience a semi-shock that leaves them unable to retort, which in turn leaves them with a gut feeling of disoriented powerlessness.

In our document analysis we kept in mind the above mentioned theoretical thinking.

\section{Findings}

The results of the analysis show parallel concerns between the early study and the follow-up documents of the Ministry in the attempt to move newcomers to their rightful central position as full fledged future citizens, away from the 'periphery' in the context of schooling or to legitimate their participation at the periphery when relevant [26] [38] [45]. Foundations, directives and strategies are now outlined in a more focused way [32], including examples of best practices and tables describing the precise roles to be played by key stakeholders, whereas earlier a more general approach was adopted [31]. As regards the 2010 document [30], it was noted that further exemplification is provided, with contextualization first, followed by the specifics for programming, assessment, including precise strategies to meet precise needs. Exemplars are given to guide teachers and programme developers for topic developments in oral communication, reading, writing and initiation to Canadian society. The major themes uncovered are presented under the following six sub-headings namely numbers and plurality, language, support, connectivity, pedagogy and transitioning.

\subsection{Maintaining strength in numbers and plu- rality}

The facilitation of acceptance into Canada and of integration that was put in place in 2004 [34] and 2005 
[33], includes good measures. However figures show a very small increase in additional numbers of FL1 newcomers to French schools. If the increase in FL1 numbers is crucial according to Immigration Canada [46], and the Ontario Government [47], especially for the survival of French schools, Canadian bilingualism and the building-up of French communities [36], one should consider accepting all interested students regardless of whether their background is French or not, an affinity with the French language and culture over the English equivalents should suffice. Of course the regional socio-economic context will impact on whether or not newcomers will be able to thrive, yet newcomers may be needed to support local community development. Because of the diversity of French origins in the newcomer population it was recommended that an expanded view of citizenship construction be created in accordance with research results [44]. An expanded dynamic was to be taken into consideration and school life was seen as allowing this to happen [42]. In the follow-up document [31] the above points were made. Revitalizing the Francophone community with newcomers is mentioned with the need to reflect on welcoming strategies along with the necessary tolerance of teachers towards language variation and varieties (p.18).

Accepted identities in French schools are listed as diverse. A brief historical overview [31] delineates the composition of the Ontario Francophone community including persons from Lower Canada (Québec) with over time additions from all over the world including Europe, the Antilles, Asia and Africa (p.11). Plurality is to be recognized [36]. Diverse knowledge bases integrated in the programmes have to be used as anchors for the study of contemporary pluralist francophone culture [31] (p.15). A fair amount of general information is given on 'acculturation', with the view to increase the French speaking contingent [30] [32].

The underlying thread of 'continued support' [31] is in line with the language policy [34] as suggested [36]. The following aspects were stressed, namely, students' increased capacity to acquire communication competencies in order to maximize learning and identity formation, school personnel's increased capacity to work in the minority context in order to support school learning and identity formation, school counsellors' increased capacity to maintain and increase numbers in French.

Furthermore, the above is fully supported through 'the cultural approach to teaching' [30] (p.6) in which the learning objectives require references made to cultural items stemming from Francophone cultures across all curriculum subject areas. By way of the cultural teaching approach [31], opportunities are also given for those coming from outside the culture to create their cultural 'francophone memory', a positive strategy to prevent a large part of 'othering' in these pupils' lives.

The new approach taken [32] appears to be a direct response to the criticism put forth [36] and offers much more flexibility than observed earlier [31]. This invitational attitude extends to being supportive of newcomer groups of families [32] (p.19) as well as having regard for places of origin [32] (p26) and is in line with previous research [7].

Moreover without stating religious diversity in the 2009 documents, attention is drawn to the changing landscape of French newcomers' origins [32] [34], namely that they no longer predominantly come from Europe but from African countries and Haïti [32] (p. 7 ). In the later document specific mention is made to religion, perhaps an indication that awareness-raising connected to this aspect was also deemed necessary [30].

Broad recruitment to French schools becomes the motto [30] (p.5) as pupils of all linguistic and cultural backgrounds are invited to become aware of the gain they make through the mastery of the two official languages of Canada, because the French school milieu is characterized by additive bilingualism. Moreover school and teacher planning are said to have to counter the negative effects of assimilation to English by creating favourable conditions for a Francophone space.

\subsection{A closer look at the language situation}

A change in attitude towards language was suggested [36]. Subsequently attitudes towards language appear much more open [32] and a significantly greater amount of support is provided for language development (p.7). An effort was made at investigating and raising awareness of existing situations to promote French schooling widely (p.8). Starting with the recognition that Canada accepts immigrants from around 143 countries to contextualize, the Ministry delineates a situation coined as 'exogamie' where in mixed culture marriages the children are not necessarily in contact with French as the dominant language (p.7). This also applies to children born in Canada. Moreover there is a hint that there needs to be a relaxation of the language policy, which in the past might have been applied too strictly. Beyond acceptance of persons entitled to an education in French as set by law, the Ministry document [32] makes mention of 'non-ayants droit' ('those not entitled by law' for schooling in French, our translation) [32] (p.4, p.27) referring to those persons outside the category referred to above [32] (p.16) and in fact meaning speakers of other languages, are now also to be given admission consideration. This shows a significant step forward towards welcoming young people in French speaking schools. 
A child with inadequate French language skills, but who has no knowledge of the other official language, was to be given the chance to be accepted in French school after prior skill upgrading based on the 2006 study [36]. Such responsibilities are now in the hands of the local schools [30]. More specifically, programme, course and support have to be provided for the pupil to acquire 'minimal competencies necessary to study and succeed according to the norm in French and in all of the other courses' (p.10, our translation). It is also suggested that pupils who had no or little knowledge of French be offered the opportunity to enroll in French development course programming and that means be devised for their induction into Canadian society through student pairing up, tutoring or peerhelp programs [30] (p.10).

The need is expressed to make students fluent in the two official languages [32] (p.18, p.20, p.26) with support to that effect in order to help them in their future personal as well as professional lives (p.28). Stated as crucial is the need that students be made aware of what it entails to become fluent in the two official languages, recognizing that "the value added of a lasting level of bilingualism and multifaceted 'francophonie' is part of the message that the French speaking school has to transmit to its school client base in order to meet the challenges faced in the contexts of recruitment and retention" (our translation, p.23).

Since open lines of communication are important across school communities, the recommendation that persons be open to using other languages to transmit information [32] (p.18, p.30) besides French and English indicates further openness to linguistic varieties and variability. This is in line with recommendations made [36] that these newcomers be accepted in the community of French speakers in order to guarantee the daily communicative use of the language with the provision that supplementary language support classes be made available for FL1 comparable to English Language Development programmes for EL1.

The previous issues around inadequate language programming [36] have been addressed head-on with specific strategies aiming at supporting 'all students' in their language development and growth as persons, the two presented hand-in-hand in a very clear, specifically articulated model and a step by step approach along four distinctive degrees, namely students with a very great need for remediation, those with a great need, those with a moderate need and those with a slight need with delineated paths [30].

\subsection{A strong support framework}

General support was not considered sufficient, individualization was also needed. What was required was directed support and for such types of support only trained personnel were deemed to be effective [19] [28]. Myers [36] recommended intercultural awareness training [29] for all school personnel, which had been reported as a major weakness. In addition to helping students in schools, family support was considered of utmost importance by a number of researchers [36] [20] [23]. Support personnel, in addition to all other school personnel, have to play a role in cultural support [31] (p.5). The heading "For a concerted action of family, school and community" [31] (p.14) shows this has been reiterated as a need as previously stated [36]. In addition, mention is made of 'community partners' as being key actors in the students' cultural lives [31] (p.15) and this would also include developing language and workplace competencies. Special programmes in cultural initiatives for community development are seen as key to the integration of Francophone culture and this includes giving newcomers responsibilities [31] (p.59), which corresponds to suggestions made earlier [36]. School is mentioned as the glue bringing families and the community together in projects [31] (p.5). This community support framework is seen as centering around the French language (p.5).

Pairing up newcomer and local families through involvement in a 10 consecutive weeks' participation in a sports, culinary or cultural activity within the school context is advocated [32] (p.20). In addition to support for parents of new students from other parents (p.19), school leaders for literacy development are made available for consultation in each school. As well, Canadian Immigration and Citizenship sponsored positions [32] (p.20) with the job title 'travailleurs d'établissement dans les écoles' (i.e. special school workers who help newcomers integrate, my translation) were created. A list of names of local community organizations is also to be provided to newcomers [32] (p.20). Moreover explicit references are made to safety and security as viewed in Canada [30] (p.58a).

Local teachers themselves are required to get adequate support and training including awareness-raising of Francophone school situations, including identity formation and character development [32] (p.34).

A school helpline is also put in place on a website with videos available in several languages to help students acquire better reading, writing and mathematical skills [32] (p.31). Thus support is provided at both macro and micro levels.

\subsection{Connectivity}

Communication through the media should be encouraged for distributed participation according to Myers [36]. Cultural organizations and media entrepreneurs of the French culture should be supported and access to their information promoted. Websites are mentioned as a source for providing support and the 
much needed information for newcomers with access to postings on the Web [31]. A very positive Internet support system appeared to be in place in many school contexts in 2006, however it was suggested that this required expansion and was to be made available to all interested persons, and not only to young people [36]. As socialization appears to be taking off via the Internet, autonomous learning and growth are also being fostered through the use of social media, Facebook, Tweeter, etc. A cautionary note points to the questioning of why such learning is not sought by either parents or teachers [31] with suggestions for remediation. Media and the Internet are said to sharpen one's hearing where appropriate and provide a chance for a better grasp of the language through its daily use [31]. It was thus recommended that both at the family and school levels, persons become technology savvy enough to include their voices to participate in local cultural developments (p.14). This statement in [31] is in line with a recommendation made in the 2006 report [36]. The dynamics of cultural identity formation are also acknowledged [31] (p.29) including a worldview (p.5) thanks to the media.

Connectivity combines a sharing of responsibilities by school council members and local school administrators who are asked to keep in mind 'regional realities' [32] (p.3) and take into account the greater Canadian context such as The Canadian Constitution and The Education Law while giving an overall message of inclusivity. Moreover, at the micro level the suggestion made of networking between newcomers' parents, encouraging school community partnerships and community projects [32] further supports recommendations made by Myers [36].

Connections with world problems, environmental education, creating a welcoming culture, using technologies, planning a career path, a competency passport and experiential learning through cooperative education are encouraged as part of an all around experience [32] (p.57).

More specifically, coordinates are given for Websites where detailed information is made available as regards a number of topics, i.e. services to facilitate integration available on the website of the CECLFCE school council, collaborative tools are mentioned to be available on Web 2.0 such as BRÉO (educational resources), SOS devoirs software (help with homework) provincial licenses and other technological resources [33] (p.29). In addition, parents are invited to view videos available in several languages [48] for help with reading, writing and mathematics [33] (p.31). Newcomer parents are also encouraged to visit the site of the National Commission of Francophone parents [32] (p.20).

Connectivity is pushed a step further through the multiple supportive roles assigned to teachers and cur- riculum intervention networks [30] (pp. 6-70) and the very clear paths set out in programming with ample examples given in a significant part of the body of the text.

\subsection{Differentiated pedagogy and leadership ability}

According to recommendations made, differentiated and systematic practices were to be re-examined in light of the variability of individual contexts and in terms of variety and variation in French language [36]. Newcomer parents were to be informed of the power they hold in the Canadian school system [36] to make the same claims for their children's skill upgrading as every other parent, in order to gain them admittance but no such mention was found in [31]. French school boards had in the past used 'insufficient language skills' as an excuse to deny newcomers access to their schools, whereas all children could attend English schools which easily topped the balance. In turn this reduced the potential increase in French speaking pupils in schools. Myers also suggested increasing community activities to bring people together [36]. Recently it was recommended that a large portion of community activities be connected to school life because of the important implications they would have both for the persons concerned and the community [31]. In the school context proper, it is considered of utmost importance to develop learners' motivation to work on observation, perception, participation, on analyzing experiences, on choosing or rejecting actions and to aim at developing initiative [31]. These needs are stressed [31], as well as the inclusion of newcomers in leadership roles (p.48) where they have responsibilities (p.59), a previously suggested desirable outcome [36].

A differentiated approach to learning should also be part and parcel of assessment [32] with special categories including knowledge and understanding, thinking abilities, communicating and applying. For all the categories the descriptors included tend to emphasize strategy and skill learning rather than concentrating solely on language use. Moreover the prescribed percentage for grading is divided between $70 \%$ for formative evaluation with the remainder $30 \%$ to be attributed to summative evaluation. In addition, summative tasks are listed as varied, i.e. reflecting the results of either an exam, an activity carried out, an essay, any other product or a combination thereof. Specific tables with descriptors are provided for each rubric [30] (pp. 3839), with four achievement levels and a concentration around efficiency, no longer only one right way to answer. Along the proposed regular curriculum documents, the programme will be providing the openness and flexibility needed in the aforementioned diverse 
contexts along individual strengths. The provided course outlines reflect the diverse spread of offerings for different background strengths.

Representativeness of diverse cultures in the teaching personnel constitutes another element to be taken into account by school councils [32]. Schools also have a responsibility in providing these new teachers the necessary guidance and training to familiarize them with the local context and inclusivity is stressed.

\subsection{Transitioning}

Transition is to be facilitated [32] by combining differentiated pedagogy and a strong support network [30] including descriptions of the roles of the student, parents, teachers, school director and community partners.

Transition considerations include programming issues starting with courses from support programmes and the possibility of half credit courses instead of the commonly known full credit ones. Explicit planning is included for these students with expectations, assessment rubrics and learning contents tied to programming until such students are able to benefit from regular courses. Specific processes are delineated as regards, for instance, oral communication with a differentiation between oral interaction and oral presentations. The approach to 'new grammar' is advocated with a concentration on speech acts and language texts.

As concerns reporting achievements, special measures are recommended for newcomers experiencing difficulties in order to allow an easier transition. Seven major guiding principles are stated, including success for all, flexibility in course work and support with adaptations for individual needs, keeping in line with best teaching practices, with teachers' key roles to be played for literacy and numeracy, with a regard to each learner's individual style, necessary community support to create a favorable learning climate for special needs learners and the recognition that each student is a unique person [30] (p.46).

The lack of follow-through was a cause for schoolleaving [36], now every small suggested step for help is stated and encouraged [32]. The Catholic 'FrancoNord' school council advocates a pairing up of parents, with each family not knowing French being supported by a French speaking parent with a student in the same grade. The help is to cover several areas, administrative details like school forms and correspondence, up to help around homework questions (p.19). Mentoring sessions for parents on the organization of the Canadian school system for newcomers, and the local context, also to be given in English for English speaking parents, are also part of initial services provided as well as being given a mentor who can also act as an interpreter (p.20). Mention is also made of the need of adult tutors (p.24) to help with school work.

Community transitioning also has to be facilitated as newcomers' families might initially only be able to maintain the cultural practices of their country of origin. The awareness of this situation is to be expanded to children born in Canada [32] and sensible support is required to help acquire the social and cultural identities that will make newcomers permeable to aspects of the new context. Examples given as transition practices include summer camp participation, French week-end camps, partnering between secondary and elementary students in school and a number of other activities to enhance socialization in French. This transition to French is also scheduled for an early start in Kindergarten [32] (p.23).

The Ministry describes very thoughtfully how the origins of the newcomer pupils require tailor-made programs of schooling [30] (p.9). In addition to the description including regular immigration according to the usual process, mention is made of emergency situations whereby people left their country of origin because of an emergency and who possibly were in transit in different countries before arriving to Canada. Such situations are said to include children separated from their family, children from war torn countries, refugees who came from camps or children who had experienced other traumatizing situations. Empathy is expressed towards children who for political, social, religious, ideological, geographical, economic or educational reasons did not have access to quality education (p.9). Special mention is made regarding preparedness to participate in provincial, national and international testing [30], yet Myers had suggested newcomers be exempt [36]. Now school administrators have the authority to postpone the test for newcomers until they have attained the adequate level in required competencies [30] (p.13) with reference made to the Provincial Office of Quality and Responsibilities in Education.

To articulate transition support at every level, different roles are described [30]. The student role entails a reflective attitude to learning and as well personal responsibility for success. Parents' roles are described in detail perhaps because their awareness-raising of Canadian schooling was a specific recommendation in the early study [36], as often parents came from countries where school work was left to school whereas in Canada, parents have responsibilities as regards understanding the curriculum, supporting their child's learning [30] (p.14) and providing educational and cultural support at the home base (p.15). The roles to be played by teachers encompass creating a supportive climate through differentiated pedagogy, proposing activities that help develop relevant strategies, taking care by giving various supports and feedback to encourage 
language development (p.16). Moreover the school administrator is responsible for adequate financial support and for ensuring the proper implementation of additional language programmes around each pupil's individually tailored plan. Even the roles to be played by the community at large are stated inasmuch as the need is stated for coordinating efforts with a coming together of school, school councils and community leaders in partnerships for educational enhancement (p.17). Roles include taking on a pro-active attitude towards pupil recruitment by running promotion campaigns [31] (p.8).

Transitioning is also given attention at micro-levels as is exemplified by the mention of the 'new grammar' approach [30] (p.33) with a focus on syntactic elements with emphasis on contextual elements without abandoning textual grammatical analysis for meaning. Bridging elements, between prior schooling practices, trends and current pedagogical needs, now help parents and teachers alike understand the focus adopted in the schools.

\section{Discussion}

As regards numbers and plurality the Ministry's visions [29] remain somewhat problematic. Mention is made of 'Francophones' from 'here and abroad' coming together through a common space to renew the local francophone culture (p.14). It is not clearly in line with the inclusivity apparent in the remainder of the document and could be perceived as cultural indoctrination because of the emphases on the Ontario Francophone culture; the responsibility to take part in new cultural developments is also noted [30]. Yet if these words are meant to convey that a culture is in constant flux (p.27), the account seems a little simplistic in the text. Normally, roles and diverse places of belonging are considered as components of identity and these should be maintained for people's emotional wellbeing.

In terms of numbers, an obvious broadening of perspectives is supported by the fact that students not entitled by law for French programming can now be admitted [32] (p.4). This could almost seem as a desperate measure to include more French students, as it is also recommended that the acceptance decision be made with the shortest waiting time and that in certain exceptional cases the process of the admission's committee can be accelerated [32] (p. 4). This is in stark contrast with earlier reported decision making at admission committee level often seen as being too selective, however it is consistent with recommendations on the concern around this question of ineffective admission strategies [36]. More refinement is provided to support the inclusivity expected at the level of admissions with a great regard for the acknowledgement of the multifaceted personal situations at play in terms of individual variability, language varieties and variation in pupils' academic preparedness due to circumstances [30]. Quite often because English is the dominant language in Ontario, newcomers choose schooling in English for their children for all the opportunities offered in the English context. English preparation courses are now offered in French schools in order to provide newcomers with programming that will allow them to join regular English classes, much as the language help provided to newcomers in English schools. Given that fluency in English can also be obtained in French schools (p.28), students have no need now to attend an English school, the added benefit of also being bilingual constitutes another factor that may improve retention.

On the one hand, as regards language, the emphasis is on the local Franco-Ontarian language. On the other hand, in terms of cultural considerations, diversity and openness to the world are stressed. This is somewhat confusing. Nonetheless, overall a great deal of flexibility is afforded students in all their language diversities. Trust is definitely a key issue but so are engaging diversity in both language and cultural differences. The awareness of the huge amount of effort required through the many different possible pathways presented will no doubt afford newcomers added possibilities. If maintaining contextual familiarity is not mentioned in [30] [31] [32] to ease language development in the same school regardless of age, mention is made however of the need to ensure continuity between the elementary and secondary school language development programs [30] (p.9). Everything is described so precisely for language development that no room is left for prejudicial treatment or at least so it appears, with specific expectations listed for speaking, reading, writing, initiation to Canadian society objectives and assessment criteria at each of the four identified levels of need [30].

Canada is not a melting pot but rather a cultural mosaic. However, little attention is given to contextual aspects in communication and acculturation [31]. In connection with community and relative to building $a$ support framework, a concerted effort involving everyone around a community is the key. What is however missing from the equation is the facilitation of communication among the isolated Francophone communities spread across the province in order to avoid duplication of effort [36], although specific localized efforts are reported [30]. To offset this oddity, mention made of the need to mediate between cultures is said to be welcomed, and cultural development to include the 
cultural mix, especially if it encourages interactions and openness. If the importance of belonging is crucial for identity formation, as I mentioned above, it need not be limited to the local community, although language and communication are placed at the core. Nevertheless accents, language varieties, creoles are also part of maintaining Francophone identity including all the traditions and practices of a culture, these will now be considered as additional and not to be replaced [30]. The interwoven action between family, school and community, favouring the coming together of persons sounds laudable except for the fact that everything appears to have to be centered around the school, with possibly too much control and not enough independent community organization initiatives. The importance of internalizing the collective culture in order to become an agent for change was also mentioned as if to correspond to identity and cultural measuring sticks (p.24), yet the concern addressed earlier was only around facilitating successful integration [36] and not going as far as assimilation in the local culture. Overall more thought was given to the intricacy involved in weaving the Canadian fabric and recommendations made are more to the point [30].

Regarding connectivity, the potential offered by the Internet and other social media for interactions among French speakers from different regions is recognized for added communication possibilities and developing an awareness of the global context. Such interactions could provide a springboard for actual Frenchspeaking student exchanges between provinces [36] but no mention of cross region interactions is made in later documents [30] [31] [32] as if sparked by concerns over retention in the province of Ontario. Despite this shortcoming, further efforts are made in the direction mentioned above [30] inasmuch as specific websites are given for access to information on a number of sensitive topics. In addition, a listing of links to access help with problem solving for a number of school councils indicates a serious effort made to argument connectivity.

Differentiated pedagogy and leadership ability are part of schooling for newcomers. The urgency lies in training members in all the constituencies concerned in intercultural awareness and communication plus identity construction for a better knowledge of ways of being in general, i.e. how to behave personally in terms of self-control in the face of the unknown, how to behave when interacting with 'otherness' [1] [2] [5] [23] [24] [40]. Promoting and enabling a change in mentality centered around cooperation, sharing resources and strategies, come with a study of the best allocation of financial support [31]. These questions were handled with a focus on leadership although the vocabulary used to describe personal gains is somewhat narrow as some notions such as 'how to get along with someone', 'how to apply a concept', are not mentioned. One important missing aspect is about how one develops the awareness of one's subconscious understanding in one's own culture, an awareness that in turn needs to be articulated, especially if it requires discussing and presenting such awareness to another cultural audience [31] (p.40). A number of steps to empower newcomers and their families were mentioned in the early study [36]. The problem however is caused by the lack of explicit strategies to be used to achieve such desirable leadership characteristics and could be seen as a major gap in communication [31]. Most interesting however is the clever way in which the development of cultural leadership in school personnel was suggested (p.48). The lack of sensibility in school personnel towards cultural otherness was deemed to be problematic [36]. The Ministry committed to publishing a guide to curb the problem. This will no doubt promote the Ministry's well explained intercultural agenda [31] (p.5-8).

Aspects of transitioning and increased empathy and openness are evident in the discourse held [30]. Aspects of the notion of leadership are reported as centering round the French language and a trusting context [30]. 'Othering' is often due to a lack of trust because of a lack of familiarity and understanding, hence the measures taken by the Ministry to make newcomers more visible through their inclusion as leaders and teachers are crucial. Although excellent measures are recommended, no mention is made of the suggestion that newcomers be left in the familiar school surroundings, when need be, rather than uprooting them again for the move from elementary to secondary school [36]. This had been suggested because language programs prior to newcomers joining the regular stream do not necessarily place students within their age group, it now seems that adequate follow-up will be provided at the secondary level; unfortunately this could imply duplication of effort. A very strict analysis of the latest document [30] shows increasing attempts to curb the number loss, i.e. the decrease in French school enrolments in Ontario. Community activities, socials, sports, a whole gamut of ways to retain newcomers in the French milieu appear to make French communities much more appealing than their English speaking counterparts. Once the realization of the huge amount of efforts required is made, hopefully French school personnel will be able to ease off and actually have the fun they deserve to have too, as controlled community outings can still be a burden. Spontaneous connections among people will hopefully provide a type of reward for the hard-working supporters of French schools. Having families of newcomers connect would be an additional blessing and strategies could be devised to strengthen such ties. On the school front, the same increased level of effort is apparent and there too, some sort of release might be necessary. Having pupils 
become more autonomous learners, at least where reviewing of prior school content is concerned would be helpful in providing faster upgrading. Self-help modules could provide the much needed anchoring in a transitional sort of way for knowledge that is already familiar but was learned in a different country and possibly in a different language. These could be level based, not in book form and more general modules. Moreover, pre-existing modules for autonomous work should somewhat alleviate the burden of schools actually providing these programmes in a continuous manner. Strong support at macro and micro levels plus instruction in the English language for additive bilingualism, as initiated in the latest documents should bear fruit in newcomers' lives in local francophone situational contexts.

\section{Conclusion}

The issue addressed was why French speaking newcomers to Canada, and more specifically to the province of Ontario, do not choose French schools. There are obvious difficulties around maintaining a second language [37] when French is competing with another regional dialect or minority language. We addressed this question [36] and resulting measures were recommended by the Ministry [30] [31] [32]. The key is also for Canada "to bring together, motivate and galvanise young people representing the diversity of minorities and majorities" as mentioned in Council of Europe documents [8]. Such an objective was recommended as worthwhile in bilingual Canada as concerns the French speaking minorities and the newcomers of French origins from diverse geographical contexts across the world. Nonetheless in the past, despite genuine efforts, the welcoming and integration policies put in place had not received enough reinforcement until the 2009 documents. In order to ensure uniformity in practices, adequate resources and on-going inservicing for the personnel in those sectors was recently given the much needed support.

In conclusion, our study shows that overall efforts made for the welcoming and integration of newcomers are positive. Most importantly admission is stressed [30] as well as welcoming and follow-through policies [32] emphasizing help for successful integration as necessary for all students and making it a whole community responsibility (p.8). Incentives in place for bilingual newcomers into schools might favour either a bilingual or a French education over the seemingly automatic choice for English speaking schools. Olson's model [38] of 'joined intentionality' (whereby ongoing dialogue between teacher and student leads to a 'a meeting of minds') can bring important cultural perspectives into play and a number of aspects of this research help shed additional light on some important issues around situated cognition [45] [26] especially in interactions between Ministry recommendations and implementations. For the benefit of all concerned, sustained collective sponsorship is required for social and economic insertions. This type of support seems to exist in ethnic, language or country specific ghettos in urban contexts. It was deemed preferable to create support structures in more non-urban contexts. Thus networks are needed to enhance the dynamics in these French speaking communities and attract French speaking newcomers to all Ontario FL1 schools. In line with recommendations made in the most recent Ministry documents [32] (p.8) in February 2009 a provincial promotional campaign for French schools was launched because of some francophone parents' unawareness of the existence of French schools in Ontario. The idea was to inform French families about French schools and all the advantages French schools offer.

The latest measures presented for implementation [30] [31] [32] want to be all encompassing and have a good chance of accomplishing what they are intended for. Recent student counts show the effort was successful as numbers in French schools are increasing whereas a decrease is reported in English school registrations. Through sustained communication with Immigration Canada officers to get pamphlets on French schools distributed to newcomers, which is presently not the case, this recently reported student growth in French schools should continue. Moreover in light of the openness of the contexts, the multifarious possibilities offered recently [30] may make newcomers to the French speaking milieu feel most welcomed and possibly contribute to their happiness, thus enabling the much sought increase in numbers. Additional efforts in developing a greater sense of responsibility, selfreflection and autonomous learning in newcomers within a supportive environment [9] [17] [20] [39] [40] will no doubt further empower them and thus the target number set by the province could become reality.

\section{References}

[1] P. Alejandro, and L. Hao, "The price of uniformity: Language, family and personality adjustment in the immigrant second generation”, Ethnic and Racial Studie, 25(6), 2002, pp. 889-912.

[2] Aronowitz, S., "Paulo Freire’s radical democratic humanism", in P. McLaren, and P. Leonard (eds.), "Paulo Freire" A critical Encounter, Routledge, New York, 1993, pp. 8-24.

[3] Bertrand-Wilcox, N., and P. Léonard, Trousse d'évaluation diagnostique: Cadre général d'insertion des élèves dans les écoles de langue française, Centre Francoontarien de ressources pédagogiques, Toronto, 2000. 
[4] M. Boler, “ All speech is not free: the ethics of 'Affirmative Action Pedagogy' ", in M. Boler (ed.), Democratic Dialogue in Education: Troubling Speech Disturbing Silence, New York, Peter Lang, 2004, pp. 4-13.

[5] Brislin, R., Understanding culture's influence on behavior, Harcourt College Publishers, Fort Worth, TX, 2000.

[6] Butler, J., Excitable Speech, Routledge, New York, 1997.

[7] Byram, M., Teaching and assessing intercultural communicative competence, Multilingual Matters Ltd, Clevedon, UK, 1997.

[8] Carneiro, I., and Knudsen, L., Fertility and family surveys in countries of the ECE region, United Nations, New York, 2001.

[9] S.P. Chamberlain, "Recognizing and responding to cultural differences in the education of culturally and linguistically diverse learners", Intervention in School and Clinic, 40 (4), 2005, pp. 195-211.

[10] CIC, Faits et Chiffres, 2001 www.cic.gc.ca, (6 March 2009).

[11] CIC, Vers la francophonie canadienne de demain, www.cic.gc.ca/francais/francophone/Canada/diversite.html, updated : 2005- 06-30 (2 March 2009).

[12] Citoyenneté et Immigration Canada, Faits et chiffres. 2002, www.cic.gc.ca, (3 March 2009).

[13] Citoyenneté et Immigration Canada, Faits et Chiffres 2004. Aperçu de l'immigration : Résidents permanents, www.cic.gc.ca/francais/pub/faits2004/permanents/6.html, (9 March 2009)

[14] Citoyenneté et Immigration Canada, www.cic.gc.ca/francais/citoyen/index.html, updated 06/02/22, (9 March 2009).

[15] Commissariat aux Langues Officielles / Official Langages Support Programs, Financial Data 2003-2004, (9 March 2009).

[16] Coderre, D., CIC Cadre Stratégique visant à favoriser l'immigration au sein des communautés francophones en situation minoritaire, 2003, November, (1 March 2009).

[17] De Certeau, M., The Capture of Speech, University of Minnesota Press, Minneapolis, 1998.

[18] M. D’anderea, J. Daniels, and R. Heck, "Evaluating the impact of multicultural counseling training”, Journal of counseling and development, 70, 1991, pp. 143-150.

[19] S. B. Garcia, and P.L. Guerra, "Deconstructing deficit: Working with educators to create more equitable learning Environments”, Education and Urban Society, 36(2), 2004 pp. 150-168.
[20] M.A. Gibson, "Promoting academic success among immigrant students: Is acculturation the issue?”, Educational Policy, 12, 1998, pp. 615-633.

[21] Goldstein, T., "Nobody is talking bad", in K. Hall, and M. Bucholtz (eds.), Gender articulated: Language and the socially constructed self , Routledge New York, 2005, pp. 375-400.

[22] Hollins, E., Culture in school learning, Erlbaum, Mawah, NJ, 1996.

[23] Jandt, F. E., An introduction to intercultural communication: Identity in a global community, SAGE Publications, Thousand Oaks, CA, 2004.

[24] Kao, G., "Psychological well-being and educational achievement among immigrant youth", in D. J. Hernandez (ed.), Children of immigrants: Health, adjustment, and public assistance, National Academic Press, Washington, DC, 1999, pp. 410-477.

[25] Kim, Y.Y., Interethnic communication. SAGE Publications, Newbury Park, CA, 1986.

[26] Lave, J., and E. Wenger, Situated Learning: Legitimate Peripheral Participation, Cambridge University Press, Cambridge, 1991

[27] C. Lawrence, "If he hollers let him go: Regulating racist speech on campus”, in M. Matsuda, C. Lawrence, R. Delgado and K. Grenshaw (eds.), Words that wound, Westview Press, Boulder, 1993, pp. 68-81.

[28] Lynch E. W., and Hanson, M. J., Developing crosscultural competence: A guide for working with young children and their families, Paul H. Brookes Publishing Co., Baltimore, 1992

[29] McLaren, P., Critical Pedagogy and predatory Culture. Routledge, London, 1995

[30] Ministère de l'Éducation de l'Ontario, Programme d'appui aux nouveaux arrivants, L'imprimeur de la Reine pour l’Ontario, Toronto, 2010.

[31] Ministère de l'Éducation de l'Ontario, Une approche culturelle de l'enseignement pour l'appropriation de la culture dans les écoles de langue française de l'Ontario: Cadre d'orientation et d'intervention, L'imprimeur de la Reine pour l’Ontario, Toronto, 2009.

[32 ] Ministère de l'Éducation de l'Ontario, L'admission, l'accueil et l'accompagnement des élèves dans les écoles de langue française de l'Ontario: Énoncé de politiques et directives, L'imprimeur de la Reine pour l'Ontario, Toronto, 2009.

[33] Ministère de l'Éducation, L'aménagement linguistique en un clin d'œil, L'imprimeur de la Reine pour l'Ontario, Toronto, 2005. 
[34] Ministère de l'Éducation, Politique d'aménagement linguistique de l'Ontario pour l'éducation en langue française, L’imprimeur de la Reine pour l'Ontario, Toronto, 2004.

[35] Ministry of Education, Antiracism and ethnocultural equity in school boards: Guidelines for policy development and implementation, Queen's printer for Ontario, Toronto, 1993.

[36] Myers, M.J., Les nouveaux arrivants dans le milieu scolaire de langue française en Ontario, Rapport de recherche pour le Ministère de l’Éducation de l’Ontario, 2006.

[37] Myers, M.J., Modalités d'apprentissage d'une langue seconde, DeBoeck Université, Bruxelles, Paris, 2004.

[38] Olson, D., Psychological Theory and Educational Reform, Cambridge University Press, Cambridge, 2003.

[39] D.L. Pao, S.D. Wang, and S. Teuben-Rowe, "Identity formation for mixed-heritage adults and implications for educators”, TESOL Quarterly, 31(3), 1997.

[40] A. Portes, and L. Hao, "The price of uniformity: Lan guage, family and personality adjustment in the immigrant second generation”, Ethnic and Racial Studies, 25 (6), 2002, pp. 889-912.

[41] C. Rothstein-Fisch, P.M. Greenfield, and E. Trumbull, "Bridging cultures with classroom strategies", Educational Leadership, 56 (7), 1999, pp. 64-66.

[42] Shweder, R., M. Minow, and H. Markus, (eds.) Engaging cultural differences, Russell Sage, New York, 2002.

[43] Université Laval, Politique d'accueil, d'encadrement et d'intégration des étudiants, 2006

www.ulaval.ca/sg/reg/Politiques/AccEncadr.html, 2006-0220, (1 March 2009).

[44] N.B. Webb, "Working with culturally diverse children and families", in N. B. Webb (ed.) Culturally diverse parentchild and family relationships-A guide for social workers and other practitioner, Columbia University Press, New York, 2001, pp. 3-28.

[45] Wenger, E., Communities of Practice: Learning, Meaning, and Identity, Cambridge University Press, Cambridge, 1998.

[46] www.cic.gc.ca/francais/citoyen/index.html, (3 March 2009).

[47]www.citizenship.gov.on.ca/french/cit div/immigrants/index.html, (3 March 2009).

[48] www.ontario.cs/abc123, (10 March 2011). 